\title{
Priority Risk Factors of Developing Cor Pumonale in Patients with Chronic obstructive Pulmonary Disease According to Correlation Analysis Findings
}

\author{
DOI: $10,17691 / \mathrm{stm} 2016.8 .4 .10$
}

Received June 16, 2016

D.A. Vakhlamov, Physician, Ultrasound Diagnostics Room";

y.A. Vakhlamov, MD, PhD, Tutor, Department of Internal Diseases Propedeutics ${ }^{2}$

1 City Clinical Hospital No.10, 43 Chongarskaya St., Nizhny Novgorod, 603011, Russian Federation;

2 Nizhny Novgorod State Medical Academy, 10/1 Minin and Pozharsky Square, Nizhny Novgorod, 603005,

Russian Federation

The aim of the investigation was to determine priority risk factors of developing cor pulmonale in patients with chronic obstructive pulmonary disease (COPD) using correlation analysis.

Materials and Methods. 71 patients with moderate and severe COPD treated in the in-patient department of City Clinical Hospital No.10 (Nizhny Novgorod) have been examined. To characterize a nutritional status, body mass index, waist measurements, waist/height ratio have been determined. Dyspnea and CPOD severity according to mMRC scale, CAT test; oxygen saturation; external respiration function values have been evaluated; Doppler echocardiographic examination has been carried out.

Results. A severe COPD course with low values of spirographic parameters correlates with pathologic remodeling of the right parts of the heart and pulmonary hypertension. An essential risk factor of developing cor pulmonale is comorbid abdominal obesity. The role of the latter especially grows in the group with severe COPD. A thoroughly conducted correlation analysis was of great value in revealing "intimate" mechanisms of developing remodeling of the right parts of the heart in chronic obstructive pulmonary disease in comorbid conditions.

Key words: chronic obstructive pulmonary disease; external respiratory function; obesity.

At present, chronic obstructive pulmonary disease (COPD) is considered as a systemic multiple syndrome pathologic process [1]. The most common comorbid diseases in COPD are ischemic heart disease, hypertension, obesity, diabetes mellitus, metabolic syndrome, osteoporosis, lung cancer, depression and other ailments [1-14]. Frequent combination of COPD and cardiovascular pathology is determined by a number of common factors: smoking, age, physical inactivity, overweight, obstructive sleep apnea, hypertensive effect of glucocorticoids, genetic predisposition [9]. COPD increases the risk of cardiovascular diseases at least two times [12], and the course of COPD is often atypical, making timely diagnosing difficult [3]. Besides, the reduction of the forced expiratory volume in 1 second (FEV1) is found to be an independent risk factor of cardiovascular mortality $[9,10]$.

A heavy uncontrolled COPD course with frequent exacerbations increases dramatically the rate of myocardial infarction incidence [13]. Metabolic syndrome may be revealed in $57.5 \%$ of COPD patients [3, 11]. Systemic inflammation, smoking, as well as genetic predisposition underlie this comorbidity $[1,3,8]$. Obesity significantly aggravates COPD, influencing spirogram values [2, 8]. Diabetes mellitus is diagnosed among the hospitalized patients with COPD in $14 \%$ of cases [7]. Availability of such serious accompanying pathological processes results in a significant worsening of patient general condition, their invalidization and the necessity to review the tactics of therapy $[1,14]$.

Presently, COPD occupies the $4^{\text {th }}$ place among the causes of mortality in the population of the world, which makes the study of the disease extremely vital [1]. Such complications of severe COPD as pulmonary hypertension, remodeling of the right parts of the heart, cardiac rate disturbance and right ventricular insufficiency are being actively investigated [15-18]. Of great interest is the definition of the risk factors of these changes in comorbid pathology in COPD patients.

The aim of the investigation was to determine priority risk factors of developing cor pulmonale in patients with chronic obstructive pulmonary disease using correlation analysis.

Materials and Methods. 71 patients with moderate $(n=45)$ and severe $(n=26)$ COPD treated in the in-patient department of City Clinical Hospital No.10 in Nizhny Novgorod have been examined (Table 1). The study complies with the Declaration of Helsinki (the Declaration

For contacts: Vladimir A. Vakhlamov, e-mail: mlpu10@mail.ru 
was passed in Helsinki, Finland, June, 1964, and revised in October, 2000, Edinburg, Scotland) and was performed following approval by the Ethic Committee of Nizhny Novgorod State Medical Academy. Written informed consent was obtained from every patient.

Duration of smoking was estimated for all patients, and a pack-year was also quantified. To characterize a nutritional status, body mass index (BMI), waist measurements (WM), waist/height ratio (WM/height) have been determined. To characterize the severity of COPD, the following parameters were assessed: dyspnea according to $\mathrm{mMRC}$ scale (a modified questionnaire of the British Medical Research Council for the assessment of dyspnea severity); indices according COPD assessment test (CAT test); oxygen saturation $\left(\mathrm{SpO}_{2}\right)$; indices of external respiratory function (ERF): forced lung capacity (FLC), forced expiratory volume in 1 second (FEV1), Tiffeneau index, peak expiratory flow rate (PEFR), momentary flow rate (MFR 25, 50 and 75), and so on.

Besides, all patients underwent Doppler echocardiography using Logiq 5 Expert ultrasound system (General electric, USA). To define mean pulmonary arterial pressure (PAPm), we used the formula suggested by Kitabatake et al. [19], which is believed to be the most optimal in case of COPD [16]. The degree of pulmonary hypertension was assessed according to a commonly accepted classification [20]. The following dimensions were also determined: the pulmonary artery trunk diameter (PATD), anterior-posterior and superiorinferior dimensions of the right atrium (APDRA and SIDRA) and ventricle (APDRV and SIDRV) at the end of the systole and diastole (e.g. APDRVs anterior-posterior dimension of the right ventricle at the end of the systole), anterior wall thickness of the right ventricle (AWRV), inferior vena cava diameter (IVC).

Statistical processing was carried out by means of Statistica 7.0 program. Criterion $\mathrm{X}^{2}$ was used for frequency comparison, while to compare two independent groups with normal parameter distribution Student t-test was applied. Special attention was paid to the correlation analysis. Pearson linear correlation (r), Spearman correlation coefficient (Rs), and Gamma criterion were calculated. In some cases, matrices of correlation coefficients were built.
Results and Discussion. It should be noted, that the examined patients were mainly at the age of slightly over 60 , and the majority of them had a long history of cigarette smoking (See Table 1). Indices of ERF demonstrated mixed disturbances of pulmonary ventilation with predominantly severe bronchial obstruction. The values of CAT test were found to be mainly high. PAPm values in the group with severe COPD corresponded to the mild degree of pulmonary hypertension. And this value in patients with moderate COPD appeared to differ statistically significantly $(p=0.001)$. The incidence of moderate pulmonary hypertension amounted to 0 and $15 \%$, respectively $\left(x^{2}=7.34 ; p=0.007\right)$, a severe degree of pulmonary hypertension was not found in the examined patients.

A marked left ventricular insufficiency was observed in $11 \%$ of patients with moderate COPD, and in $44 \%$ with a severe course $\left(X^{2}=4.26 ; p=0.039\right)$. The incidence of hypertension was 91 and $72 \%$, respectively. Obesity was diagnosed in 31 and $50 \%$ of patients, and only one patient with severe COPD had an insufficient body mass.

The most important risk factors of pulmonary

Table 1

Characteristic of the examined patients with chronic obstructive pulmonary disease

\begin{tabular}{|c|c|}
\hline Index & Mean values \\
\hline Age (years) $(M \pm m)$ & $62.87 \pm 8.09$ \\
\hline A number of smokers (\%) & 93 \\
\hline Smoking duration (years) $(\mathrm{M} \pm \mathrm{m})$ & $38.76 \pm 11.46$ \\
\hline COPD duration (years) (Me [25; 75]) & $10[3 ; 20]$ \\
\hline $\mathrm{FLC}(\%)(\mathrm{M} \pm \mathrm{m})$ & $52.07 \pm 16.86$ \\
\hline FEV1 (\%) (M $\pm m)$ & $42.98 \pm 17.62$ \\
\hline Tiffeneau index (Me [25; 75]) & $67.0[54.0 ; 81.5]$ \\
\hline PEFR (\%) (M $\pm m)$ & $39.48 \pm 14.47$ \\
\hline $\mathrm{SpO}_{2}(\%)(\mathrm{Me}[25 ; 75])$ & $94[90 ; 96]$ \\
\hline Dyspnea according to mMRC test (points) (Me [25; 75]) & $2[1 ; 2]$ \\
\hline CAT test indices (points) $(\mathrm{M} \pm \mathrm{m})$ & $22.89 \pm 7.58$ \\
\hline PAPm (modrate COPD) (Me [25; 75]) & $29.9[26.3 ; 34.0]$ \\
\hline PAPm (severe COPD) (Me [25; 75]) & $34.0[29.55 ; 39.35]$ \\
\hline
\end{tabular}

Table 2

Correlations ( $r$ ) between the severity of chronic obstructive pulmonary disease course and remodeling of the right parts of the heart $(n=71)$

\begin{tabular}{lcccc}
\multicolumn{1}{c}{ Index } & APDRVd & SIDRVd & APDRAs & APDRAd \\
\hline $\mathrm{SpO}_{2}$ & $-0.243 ; p=0.046$ & $-0.108 ; p=0.382$ & $-0.005 ; p=0.966$ & $-0.025 ; p=0.841$ \\
\hline mMRC test & $0.305 ; p=0.011$ & $0.284 ; p=0.019$ & $0.218 ; p=0.074$ & $0.208 ; p=0.088$ \\
CAT test & $0.074 ; p=0.547$ & $0.013 ; p=0.913$ & $0.111 ; p=0.365$ & $0.081 ; p=0.509$ \\
\hline
\end{tabular}


hypertension and remodeling of the right parts of the heart in COPD are supposed to be:

long-term and intensive smoking;

severity of the disease itself;

concomitant left ventricular insufficiency;

obesity, primarily visceral, and so on.

The concomitant left ventricular insufficiency is not discussed in this work. We failed to estimate the correlation between the duration and intensity of smoking, on the one hand, and remodeling of the right parts of the

\begin{tabular}{|c|c|c|c|}
\hline $\begin{array}{c}\mathrm{r}=-0.533 ; \\
p=0.034\end{array}$ & $\begin{array}{c}\text { Tiffeneau } \\
\text { index }\end{array}$ \\
\hline $\begin{array}{c}\mathrm{r}=-0.458 ; \\
\mathrm{p}=0.074\end{array}$ & MFR 25 \\
\hline
\end{tabular}

Figure 1. Correlations between the indices of external respiratory function and pulmonary hypertension in patients with severe chronic obstructive pulmonary disease

Table 3

Correlations ( $r$ ) between the parameters of nutritional status, pulmonary hypotension and right atrium dimensions in patients with moderate chronic obstructive pulmonary disease $(n=45)$

\begin{tabular}{lccc}
\multicolumn{1}{c}{ Index } & PAPm & SIDRAs & SIDRAd \\
\hline BMI & $0.317 ; p=0.034$ & $0.662 ; p=0.000$ & $0.562 ; p=0.001$ \\
WM $(\mathrm{cm})$ & $0.317 ; p=0.034$ & $0.509 ; p=0.002$ & $0.365 ; p=0.034$ \\
WM/height & $0.282 ; p=0.060$ & $0.451 ; p=0.007$ & $0.296 ; p=0.089$ \\
\hline
\end{tabular}

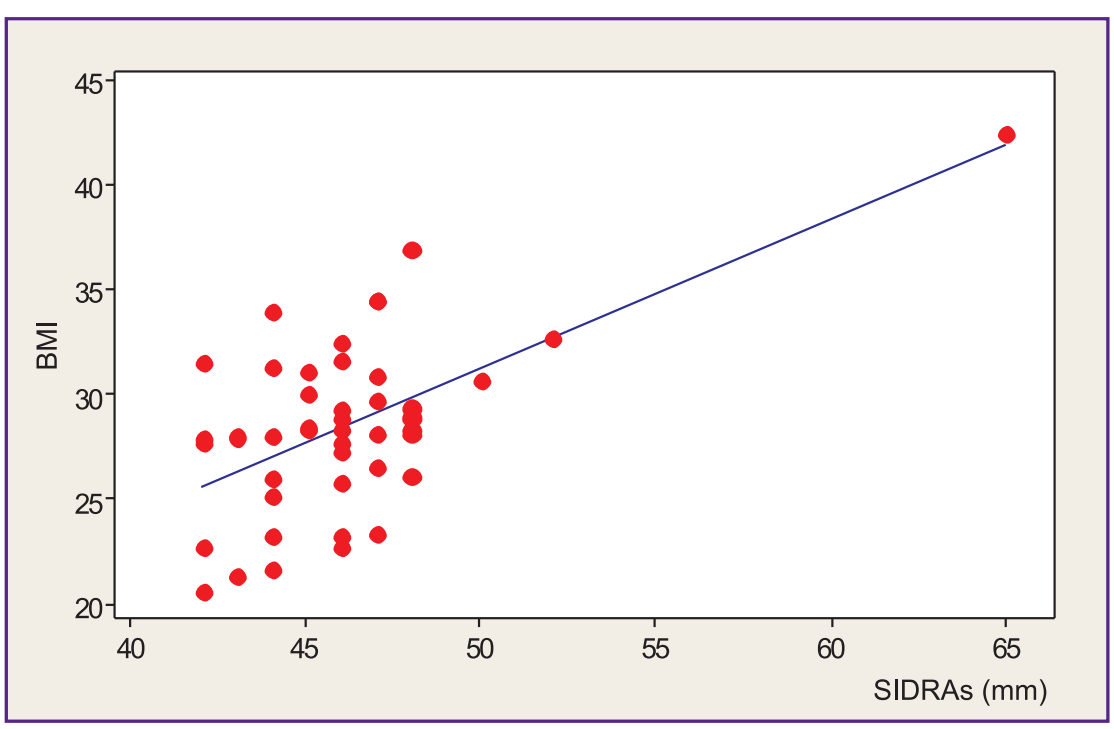

Figure 2. Correlation between body mass index and superior-inferior dimension of the right atrium in systole in patients with moderate chronic obstructive pulmonary disease $(n=45)$ heart and pulmonary hypertension, on the other. Various indices of COPD severity demonstrated associations with PAPm. Thus, there was revealed a positive correlation of parameter with dyspnea according to mMRC scale

Indices of remodeling of the right parts of the heart correlated with COPD severity in different ways (Table 2). APDRVd correlated negatively with $\mathrm{SpO}_{2}$ and positively with the dyspnea degree according to mMRC scale. A statistically significant dependence of SIDRVd on dyspnea value was found. The correlation of dyspnea with anterior-posterior dimensions of the right atrium in systole and diastole was at the level of statistical tendency.

Parameters of ERF correlated well with ultrasound indices of pulmonary hypertension. So, in the group of patients with severe COPD without marked left ventricular insufficiency $(n=18)$, PATD value demonstrated statistically significant negative connections actually with all ventilation constants. Index PAPm positively correlated with FEV1 (Figure 1). Association of PAPm with MFR 25 was at the level of statistical tendency $(r=-0.458 ; p=0.074)$.

The detected correlations between the nutritional status and Doppler echoCG parameters became an interesting finding for us. They appeared to be illustrative enough in the moderate COPD group $(n=45)$ (Table 3). Index PAPm positively correlated with BMI and WM, SIDRAs was in the statistically significant positive relations with all indices of the nutritional status (See Table 3, Figure 2). SIDRAd demonstrated statistically significant correlation with BMI and WM. It should be noted that in this group of patients anterior-posterior dimensions of the right atrium in contrast to superiorinferior ones did not increase in connection with obesity. Moreover, no correlations between nutritional status and dimensions of the right ventricle were found.

In numerous investigations, carried out previously [17, 18, 21], it has been said, that cardiac remodeling in chronic bronchopulmonary pathology is caused not only by the pressure increase in the pulmonary artery 
Table 4

Correlations between the parameters of nutritional status and remodeling of the right parts of the heart in patients with severe chronic obstructive pulmonary disease

\begin{tabular}{lcccccc}
\hline \multicolumn{1}{c}{ Index } & AWRV $^{*}$ & APDRAs $^{*}$ & SIDRAs $^{*}$ & APDRAd $^{*}$ & SIDRAd $^{*}$ & IVC (mm $)^{* *}$ \\
BMI & $r=0.507 ;$ & $r=0.407 ;$ & $r=0.321 ;$ & $r=0.407 ;$ & $R S=0.369 ;$ & $r=0.447 ;$ \\
& $p=0.016$ & $p=0.039$ & $p=0.110$ & $p=0.039$ & $p=0.063$ & $p=0.072$ \\
WM (cm) & $r=0.499 ;$ & $r=0.442 ;$ & $r=0.419 ;$ & $r=0.458 ;$ & $r=0.425 ;$ & $r=0.434 ;$ \\
& $p=0.018$ & $p=0.024$ & $p=0.033$ & $p=0.019$ & $p=0.030$ & $p=0.081$ \\
WM/height & $r=0.487 ;$ & Gamma=0.327; & Gamma=0.275; & Gamma=0.320; & Gamma $=0.320 ;$ & $R S=0.419 ;$ \\
& $p=0.022$ & $p=0.024$ & $p=0.059$ & $p=0.027$ & $p=0.027$ & $p=0.093 ;$ \\
& & & & & & Gamma $=0.353 ;$ \\
& & & & & & $p=0.087$ \\
\hline
\end{tabular}

N o t e: * all seriously ill patients $(n=26) ;{ }^{* *}$ seriously ill patients without prominent left ventricular insufficiency $(n=18)$.

(hemodynamic theory), but by the activation of different neurohumoral factors as well.

The correlation analysis in the group with a severe course $(n=26)$ showed a somewhat different picture. Nutritional status parameters in this cohort correlated positively and statistically significantly with AWRV thickness (Table 4). Additionally, there were revealed numerous links between the obesity degree and the right atrium dimensions in systole and diastole, not only superior-inferior but anterior-posterior as well. Correlations of nutritional status indices with IVC diameter were at the level of statistical tendency. Thus, a heavy course of COPD results in essentially more prominent changes of the right atrium geometry and the development of cor pulmonale.

Conclusion. A severe course of chronic obstructive pulmonary disease with low values of spirographic parameters correlates with pathological remodeling of the right parts of the heart and pulmonary hypertension. An essential risk factor of cor pulmonale development is comorbid abdominal obesity. The role of the latter especially grows in the group with severe chronic obstructive pulmonary disease. In our work, we failed to demonstrate a direct negative impact of intensive cigarette smoking on the development of cor pulmonale. A thoroughly conducted correlation analysis was of great value in revealing "intimate" mechanisms of developing remodeling of the right parts of the heart in chronic obstructive pulmonary disease in comorbid conditions.

Study Funding and Conflicts of Interest. The work was not supported by any financial source, and there is no conflicts of interest related to this study.

\section{References}

1. Global'naya strategiya diagnostiki, lecheniya i profilaktiki khronicheskoy obstruktivnoy bolezni legkikh (peresmotr $2014 \mathrm{~g}$.) [Global strategy of diagnosis, treatment and prevention of chronic obstructive pulmonary disease (revised in 2014)]. Pod red. Belevskogo A.S. [Belevskiy A.S. (editor)]. Moscow: Rossiyskoe respiratornoe obshchestvo; 2014.
2. Vasil'kova T.N., Antipina A.N., Popova T.N., Sorokin D.V. Clinical features and pathogenetic mechanisms of chronic obstructive pulmonary disease progressing concurrently with obesity. Meditsinskaya nauka i obrazovanie Urala 2008; 9(4): 8-10.

3. Filatova Yu.I., Perfil'eva M.V., Chernov A.V. Specific features of clinical picture and therapy of chronic obstructive pulmonary disease accompanying by metabolic syndrome. Molodoy uchenyy 2014; 7: 220-222.

4. Couillard A., Veale D., Muir J.F. Comorbidities in COPD: a new challenge in clinical practice. Rev Pneumol Clin 2011; 67(3): 143-153, https://doi.org/10.1016/j.pneumo.2010.05.003.

5. Karoli N.A., Rebrov A.P. Modern approaches to the treatment of chronic heart failure in patients with chronic obstructive pulmonary disease. Consilium medicum 2014; 16(3): 13-22.

6. Karoli N.A., Rebrov A.P. Chronic obstructive pulmonary disease and cardiovascular pathology. Klinitsist 2007; 1: 13-19.

7. Romashov B.B., Polyakova N.V. Characteristic features of the pathogenesis, clinical picture and treatment of chronic obstructive pulmonary disease combined with diabetes mellitus. Molodoy uchenyy 2015; 13: 310-314.

8. Ryazanov A.S., Kireev S.A., Eremenko N.N. Specific features of COPD clinical course in metabolic syndrome: the role of systemic inflammation. Ozhirenie i metabolizm 2010; 2: 49-51.

9. Ryazanov A.S., Kireev S.A., Eremenko N.N. Spirographic characteristics of patients with COPD and metabolic syndrome depending on a body mass. Ozhirenie $i$ metabolizm 2010; 3: 28-30.

10. Ovcharenko S.I., Leshchenko I.V. Chronic obstructive pulmonary disease and concomitant cardiovascular pathology. Approaches to patient managing. Consilium medicum 2015; 1 : 10-13.

11. Sin D.D., Anthonisen N.R., Soriano J.B., Agusti A.G. Mortality in COPD: role of comorbidities. Eur Respir J 2006; 28(6): 1245-1257, https://doi. org/10.1183/09031936.00133805.

12. Park S.K., Larson J.L. Metabolic syndrome and associated factors in people with chronic obstructive pulmonary disease. West J Nurs Res 2014; 36(5): 620-642, https://doi. org/10.1177/0193945913512423. 


\section{CLINICAL MEDICINE}

13. Donaldson G.C., Hurst J.R., Smith C.J., Hubbard R.B., Wedzicha J.A. Increased risk of myocardial infarction and stroke following exacerbation of COPD. Chest 2010; 137(5): 1091-1097, https://doi.org/10.1378/chest.09-2029.

14. Arutyunov G.P. Patient with chronic obstructive pulmonary disease: a cardiologist's view. Pul'monologiya $i$ allergologiya 2012; 4: 15-18.

15. Bugaenko V.V. Heart ischemic and chronic obstructive pulmonary diseases. Ratsional'naya farmakoterapiya 2012; 3 : 63-69.

16. Alekhin M.N., Dukova N.A., Zateishchikova A.A., Kiselev D.G., Shavrin I.V., Privalov D.V., Vtorushin D.V., Sidorenko B.A., Zateishchikov D.A. Echocardiographical evaluation of mean pulmonary artery pressure in patients with chronic obstructive pulmonary disease. Kardiologiya 2010; 50(9): 41-46.

17. Bigaeva D.U., Daurova M.D., Gatagonova T.M., Bolieva L.Z. Features of structurally functional changes of cardiovascular system in patients with arterial hypertension and chronic obstructive pulmonary disease. Sovremennye problemy nauki i obrazovaniya 2014; 4. URL: https://www.scienceeducation. ru/ru/article/view?id=14483.

18. Ryabova A.Yu. Osobennosti remodelirovaniya serdtsa u bol'nykh bronkhial'noy astmoy i khronicheskoy obstruktivnoy bolezn'yu legkikh. Avtoref. dis. ... kand. med. nauk [Cardiac remodeling in patients with bronchial asthma and chronic obstructive pulmonary disease. PhD Thesis]. Saint Petersburg; 2008.

19. Kitabatake A., Inoue M., Asao M., Masuyama T., Tanouchi J., Morita T., Mishima M., Uematsu M., Shimazu T., Hori M., Abe H. Noninvasive evaluation of pulmonary hypertension by a pulsed Doppler technique. Circulation 1983; 68(2): 302-309, https://doi.org/10.1161/01.cir.68.2.302.

20. Reznik E.V., Gendlin G.E., Strozhakov G.I. Ekhokardiografiya $v$ praktike kardiologa [Echocardiography in the practice of a cardiologist]. Moscow: Praktika; 2013; 212 p.

21. Nekrasov A.A., Kuznetsov A.N., Mel'nichenko O.V., Kruglova I.S. The cardiac remodeling of patients with chronic obstructive pulmonary disease. Meditsinskiy al'manakh 2011; 3(16): 112-115. 